\title{
THE USE OF GREEN TEA IN THE WEIGHT LOSS PROCESS: A REVIEW OF THE LITERATURE
}

\author{
Ana Flávia Alves Nogueira ${ }^{1}$, Maria Jardeane Lopes Pereira ${ }^{2}$ e Maria do Socorro Moura Rufino ${ }^{1,2 *}$ \\ ${ }^{1}$ Mestrado Acadêmicoem Sociobiodiversidade e Tecnologias Sustentáveis (MASTS), Universidade da Integração \\ Internacional da Lusofonia Afro-Brasileira, Redenção-CE, Brasil \\ 2Instituto de Desenvolvimento Rural (IDR), Universidade da IntegraçãoInternacional da Lusofonia Afro- \\ Brasileira (UNILAB), Redenção-CE, Brasil
}

\section{ARTICLE INFO}

\section{Article History:}

Received $20^{\text {th }}$ May, 2021

Received in revised form

$19^{\text {th }}$ June, 2021

Accepted $20^{\text {th }}$ July, 2021

Published online $26^{\text {th }}$ August, 2021

\section{Key Words:}

Green Tea, Obesity, Overweight,

Camellia sinensis.

*Corresponding author:

Maria do Socorro Moura Rufino

\begin{abstract}
A disease that generates great concern worldwide is obesity, through which the accumulation of body fat can result in the increase of other health problems. The use of plants is evolving every day as a strategy for weight reduction and one of the treatment methods that is expanding the most is the consumption of green tea. The objective of this study was to conduct a review of the last five years of studies on the use of green tea and its effects on weight loss. As a research strategy, it was used data available in the platforms: Pubmed, Scielo, Lilacs and Google Scholar. However, the studies analyzed on green tea for weight loss and prevention of obesity indicate that there are better results when it is associated with physical activity, diet and specialized monitoring.
\end{abstract}

Copyright (C) 2021, Ana Flávia Alves Nogueira et al. This is an open access article distributed under the Creative Commons Attribution License, which permits unrestricted use, distribution, and reproduction in any medium, provided the original work is properly cited.

Citation: Ana Flávia Alves Nogueira, Maria Jardeane Lopes Pereira e Maria do Socorro Moura Rufino. 2021. "The use of green tea in the weight loss process: a review of the literature", International Journal of Development Research, 11, (08), 49381-49384.

\section{INTRODUCTION}

É do conhecimento dos profissionais de saúde que a obesidade se tornou um dos maiores problemas de saúde pública mundial nas últimas décadas e que o número de pessoas com esta morbidade aumenta a cada dia. Segundo dados da Associação Brasileira para o Estudo da Obesidade e da Síndrome Metabólica - ABESO (2020), estima-se que em 2025, cerca de 2 bilhões de adultos ao redor do mundo estarão acima do peso, sendo cerca de 700 milhões de indivíduos com obesidade, isto é, com índice de massa corporal (IMC) igual ou superior a $30 \mathrm{~kg} / \mathrm{m}^{2}$. A obesidade é uma desordem no equilíbrio energético, causando acúmulo excessivo de gordura corporal, tornando-se assim, uma doença preocupante e alarmante no mundo por evidenciar o surgimento de outras doenças (ALTERIO, 2007). No Brasil, a obesidade aumentou $67,8 \%$ nos últimos treze anos, saindo de $11,8 \%$ em 2006 para $19,8 \%$ em 2018. A maior taxa de crescimento foi entre adultos de 25 a 44 anos, dentre estes, a maioria são mulheres (VIGITEL, 2018). Várias são as estratégias utilizadas por indivíduos obesos na tentativa de reduzir o excesso de peso, algumas delas até alcançam algum sucesso. Nestas circunstâncias, vem crescendo a busca por novos tratamentos alternativos, assim como, o interesse na utilização de compostos fitoquímicos, extraídos de plantas medicinais (ALTERIO, 2007). alívio e cura de doenças, através da ingestão de infusões de partes de plantas medicinais - os chás, sendo esta uma das mais remotas formas de tratamento e cura de enfermidades da humanidade (PAZINATO et al., 2012). O chá é uma das bebidas mais consumidas no mundo, perdendo somente para a água. Antigamente, o consumo deste produto era concentrado em países da Ásia e Europa, o que vem mudando nos últimos anos. Além do seu aroma e sabor, um dos argumentos para explicar seu uso é sua finalidade como alimento funcional, que demonstra resultados positivos na redução de peso, no controle da obesidade e em outras doenças (DUARTE et al., 2014; MATSUBARA E RODRIGUEZ-AMAYA, 2006). Dentre os chás mais conhecidos e comercializados com propriedade emagrecedora e termogênica, está o chá verde advindo da Camelliasinensis. O chá verde é produzido a partir da infusão das folhas desta planta, assim como o chá branco, o chá vermelho, o chá preto e o oolong, são extraídos do mesmo vegetal, sendo a diferença apenas no grau de maturação e fermentação das folhas (ARRAES e FUNCHAL, 2016). $\mathrm{O}$ efeito termogênico do chá está associado à presença das catequinas (principalmente a epigalocatequinagalato - EGCG) e da cafeína (DULLOO et al., 1999 citado por SAING E SILVA, 2009). A Camelliasinensis é uma espécie originária do Sudeste Asiático, principalmente China e Índia, mas também existente em outras regiões e em países de clima ameno e úmido, sendo a de origem chinesa, a que apresenta melhor qualidade (SOARES et al., 2007; ANNELLI, 2016). Os estudos acerca do chá verde vêm crescendo a 
cada dia e têm despertado interesse dos pesquisadores devido à presença destes compostos fenólicos, que são substâncias químicas importantes para os seres humanos, por apresentar propriedades farmacológicas que favorecem sistemas biológicos de defesa (URZEDO, 2020). As catequinas presentes no chá são responsáveis por propriedades que impedem a oxidação de LDL- colesterol, assim como, demonstra eficácia na redução de gordura corporal e prevenção da obesidade (MELO et al., 2009). Portanto, a presente pesquisa objetiva realizar uma revisão de trabalhos dos últimos cinco anos quanto ao uso do chá verde e seus efeitos sobre o peso corporal.

\section{METODOLOGIA}

Esta pesquisa trata-se de um estudo retrospectivo, descritivo e qualitativo de revisão de literatura, que consiste em uma busca criteriosa de publicações com a finalidade de aprimorar a visão crítica sobre estes estudos científicos e correlacionar o uso do chá verde sobre o excesso de peso. Como estratégia de busca, utilizou-se de dados disponíveis nas plataformas: Pubmed, Scielo, Lilacs e Google Acadêmico publicados entre o período de 2016 a 2021. O critério atribuído para escolha dos artigos foi a inclusão do assunto: chá verde $\mathrm{x}$ emagrecimento, chá verde $\mathrm{x}$ perda de peso e chá verde $\mathrm{x}$ obesidade. No total, 22 artigos foram inicialmente encontrados, por seguinte, foram separados os que tratavam da temática de interesse: chá verde $\mathrm{x}$ emagrecimento e atendiam ao período estabelecido.

\section{RESULTADOS E DISCUSSÃO}

Após a busca e análise dos trabalhos, foram identificados 10 artigos com a temática. Para uma melhor visualização, os resultados são apresentados na Tabela 1. peso e controle da obesidade - uma preocupante doença para saúde pública mundial. Quanto à composição química do chá verde, apontase uma grande quantidade de catequinas que apresentam importância para humanos pela sua ação antioxidante, além de auxiliarem no tratamento de diversas doenças, dentre elas, a redução de gordura corporal. Em contrapartida, o consumo do chá deve ser equilibrado para não gerar efeitos indesejados, como problemas de insônia, gastrointestinais, assim também, como o acompanhamento com especialista é indispensável. Para os autores Gindro e Veras (2018), os benefícios do chá verde na redução do peso estão ligados aos efeitos dos compostos fenólicos, principalmente em relação à sua ação antioxidante. Além da dose adequada, a união de atividade física e hábitos alimentares saudáveis, pode ainda, gerar resultados mais expressivos em relação as doenças ligadas à obesidade. $\mathrm{O}$ mesmo é corroborado por Fernandes et al. (2017), relatando que, além dos efeitos antioxidantes, há evidências entre a ação da catequina e a perda de peso e que outro aliado do emagrecimento é a associação do chá à prática de atividade física.

Além disso, os autores complementam que, para obter os efeitos benéficos do chá verde, sugere-se o consumo de quatro a seis xícaras ao dia, entre as refeições para não haver interações com os nutrientes dos alimentos, mantendo sua biodisponibilidade. Anelli et al. (2016), ressaltam que a absorção das catequinas é realizada no intestino (delgado ou cólon) e que o metabolismo é efetuado através da ação de enzimas hepáticas. As catequinas de melhor absorção são a epigalocatequinagalato (EGCG) e epicatequina (EC). Porém, se a EGCG for administrada isoladamente sua biodisponibilidade é menor, portanto, para que possa exercer um bom efeito sobre o tecido adiposo é necessário a absorção de todas as catequinas e dos outros compostos presentes no chá verde, inclusive a cafeína. Além disso, também menciona que a associação com atividade física e uma boa alimentação potencializa os efeitos sobre a gordura corporal, dado

Tabela 1. Resultados dos artigos analisados considerando título da obra, autor, ano da publicação, periódico e assunto abordado

\begin{tabular}{|c|c|c|c|}
\hline TÍTULO & AUTOR/ANO & PERIÓDICO & ASSUNTO \\
\hline $\begin{array}{l}\text { Chá verde (Camelliasinensis): } \\
\text { alternativo da obesidade }\end{array}$ & Luz et al., (2016) & Google acadêmico & $\begin{array}{l}\text { Revisar na literatura científica a ação e mecanismos } \\
\text { fisiológicos do chá verde no tratamento da } \\
\text { obesidade }\end{array}$ \\
\hline $\begin{array}{l}\text { Benefícios do chá verde associado ao } \\
\text { emagrecimento }\end{array}$ & $\begin{array}{lll}\text { Gindro } & \text { e } & \text { Veras } \\
(2018) & & \end{array}$ & Google acadêmico & $\begin{array}{l}\text { As principais ações e propriedades funcionais do } \\
\text { chá verde no efeito da perda de massa corporal }\end{array}$ \\
\hline $\begin{array}{l}\text { Efeitos do chá verde e do exercício físico sobre } \\
\text { a composição corporal de pessoas obesas }\end{array}$ & $\begin{array}{l}\text { Fernandes et al., } \\
(2017)\end{array}$ & Google acadêmico & $\begin{array}{l}\text { Revisão sistemática de literatura sobre o consumo } \\
\text { do chá verde associado ao exercício físico como } \\
\text { uma ferramenta do controle de peso }\end{array}$ \\
\hline $\begin{array}{l}\text { Efeitos funcionais das catequinas do chá verde } \\
\text { na redução de gordura corporal }\end{array}$ & Annelli et al., (2016) & Google Acadêmico & $\begin{array}{l}\text { Estudo dos compostos bioativos do chá verde e seus } \\
\text { efeitos funcionais na redução de gordura corporal }\end{array}$ \\
\hline $\begin{array}{l}\text { Influência dos polifenóis do chá verde na } \\
\text { obesidade }\end{array}$ & $\begin{array}{l}\text { Arraes e Funchal } \\
(2017)\end{array}$ & Google acadêmico & $\begin{array}{l}\text { Revisar a influência dos polifenóis do chá verde e } \\
\text { seus possíveis mecanismos de ação na redução de } \\
\text { gordura }\end{array}$ \\
\hline $\begin{array}{l}\text { A influência do Chá verde (Camelliasinensis) } \\
\text { na redução do peso corporal }\end{array}$ & $\begin{array}{l}\text { Moresco e Ghisleni } \\
(2017)\end{array}$ & Google acadêmico & $\begin{array}{l}\text { Revisar a influência do chá verde sobre a redução do } \\
\text { peso corporal }\end{array}$ \\
\hline $\begin{array}{l}\text { Nutracêuticos para o emagrecimento: uma } \\
\text { revisão }\end{array}$ & $\begin{array}{l}\text { Nascimento; Piloto e } \\
\text { Tiyo, (2017) }\end{array}$ & Google acadêmico & $\begin{array}{l}\text { Revisar sobre o uso sugestivo de nutracêuticos para } \\
\text { o tratamento de DCNT e na redução do risco de } \\
\text { obesidade. }\end{array}$ \\
\hline $\begin{array}{l}\text { Uso potencial do chá verde no tratamento } \\
\text { complementar de morbidades e uso de } \\
\text { medicamentos, associado ao envelhecimento: } \\
\text { uma revisão }\end{array}$ & Martins et al., 2021 & Google acadêmico & $\begin{array}{l}\text { Revisar a literatura sobre o uso potencial do chá } \\
\text { verde (Camelliasinensis) no tratamento } \\
\text { complementar de morbidades e uso de } \\
\text { medicamentos, associado ao envelhecimento }\end{array}$ \\
\hline
\end{tabular}

Fonte: Autores (2021).

Segundo Luz et al. (2016), o uso do chá verde combinado com exercício físico e uma dieta balanceada é um método para o controle do peso. Isso porque os polifenóis e flavonoides presentes no chá, inibem uma enzima que atua na degradação do neurotransmissor responsável pelo controle da quantidade de adipócitos - células que armazenam muita gordura. Entretanto, ressalta a escassez de pesquisa sobre a atuação do chá diretamente em seres humanos. Pires et al. (2021), destaca o uso da fitoterapia como alternativa para redução de reforçado pelos estudos de Lin et al. (2005). Arraes e Funchal (2016), revisaram os estudos acerca da influência dos polifenóis do chá verde na obesidade e observaram que indivíduos com excesso de peso que fizeram uso do chá verde tiveram um aumento na oxidação dos ácidos graxos, na estimulação da lipólise e na termogênese, contribuindo com a melhora do quadro de obesidade. Os efeitos exercidos pelo chá verde também foram observados sobre o perfil glicídico (insulina e glicemia) e lipídico (colesterol total e suas frações). Entretanto, segundo estes autores, o mecanismo de ação do chá verde sobre a 
lipólise ainda não está bem elucidado apesar de existir várias hipóteses. Já Moresco e Ghisleni (2017), destacaram a influência do chá verde sobre a redução do peso corporal. A mesma, foi comprovada principalmente quando ocorre associação da bebida com a prática regular de atividade física e dieta balanceada, porém, ressaltam que ainda são necessárias mais pesquisas referentes ao uso da Camelliasinensis no emagrecimento e também no que tange a dose adequada, toxicidade e efeitos adversos relacionados ao uso prolongado sobre a saúde humana. Vilela e Souza (2016), analisaram os resultados obtidos pela utilização do chá verde, considerando seus benefícios no processo de emagrecimento e estratégia alternativa para o tratamento e prevenção da obesidade. Constataram que as substâncias contidas no chá verde que exercem essa atividade preventiva sobre o excesso de peso são as catequinas e a cafeína, que atuam sobre o sistema nervoso simpático ativando seus efeitos termogênicos. Além disso, destacaram outros benefícios como: ação antioxidante, controle sobre o diabetes, as dislipidemias e as doenças cardiovasculares. Outras pesquisas sobre efeitos colaterais e interações medicamentosas ainda precisam ser realizadas para auxiliar a prescrição e orientação por parte dos profissionais de saúde, inclusive os nutricionistas.

Nascimento; Piloto e Tiyo (2017), avaliaram o impacto do uso de produtos nutracêuticos sobre as doenças crônicas não transmissíveis (DCNT), incluindo a obesidade, dentre estes, destacaram os alimentos funcionais, como o chá verde. Os estudos evidenciaram que o chá verde, adquirido através das folhas frescas da erva Camelliasinensis, apresentaram alta quantidade de flavonóides conhecidos como catequinas, substâncias estas que são capazes de favorecer a redução de peso e gordura corporal, auxiliar na prevenção e tratamento da obesidade e de outras doenças associadas a ela. Os estudos revisados destacam que os flavonóides auxiliam na prevenção de diversas doenças crônicas não transmissíveis quando consumidos através da alimentação, devido sua ação: antioxidante, hipoglicemiante, antitumoral, antiinflamatória e antiaterogênica. Segundo Nascimento; Piloto e Tiyo (2017), os possíveis mecanismos de ação do chá verde sobre a obesidade são: 1) Redução expressiva do gasto de glicose celular acompanhado pela redução da translocação do transportador de glicose (GLUT4) no tecido adiposo, enquanto este, estimula o gasto de glicose no músculo esquelético e 2) Supressão da expressão e/ou ativação da adipogênese relacionada a fatores de transcrição (ação sobre o sistema nervoso simpático). Martins et al (2021), revisaram a literatura sobre o uso potencial do chá verde como tratamento complementar de morbidades e o uso de medicamentos relacionados ao envelhecimento. Destacaram entre as morbidades a obesidade e corroboraram quanto a composição do chá, ou seja, quanto a presença de cafeína e catequinas, principalmente a EGCG e seu efeito sobre a termogênese e oxidação de gordura. Os resultados obtidos por eles em sua revisão e citados por Alterio; Fava e Navarro (2007), revelaram que os indivíduos que utilizaram as catequinas no tratamento para redução de peso alcançaram melhores resultados quanto à termogênese. Também citaram o estudo de Senger et al. (2012), que evidenciou a eficácia do chá verde sob a diminuição do perímetro abdominal de idosos com síndrome metabólica e, que apesar dos estudos com chá verde em idosos com DCNT serem poucos e inconclusivos, a MTC (Medicina Tradicional Chinesa) utiliza a Camelliasinensis há muitos anos para prevenir e tratar doenças.

\section{CONCLUSÃO}

Através da pesquisa bibliográfica realizada foi possível analisar o avanço do uso de chá verde no processo de emagrecimento. Foi evidenciado que a planta base para o preparo do chá tem grande presença de compostos fenólicos, como os flavonoides e catequinas, no qual apresentam mecanismos relacionados à perda de peso ou no tratamento de outras enfermidades. Ademais, dentre os estudos sobre o chá verde no combate e prevenção da obesidade apontam que há melhores resultados quando associado à prática física, alimentação e acompanhamento especializado. Entretanto, ainda persiste a necessidade de experimentos acerca da utilização da bebida e seus efeitos na saúde humana.

\section{REFERÊNCIAS}

Abeso. Associação Brasileira para o Estudo da Obesidade e da Síndrome Metabólica. Disponível em: https://abeso.org.br/osultimos-numeros-da-obesidade-no-brasil/. Acesso em: 08/07/ 2021.

Alterio, AA.; Fava, DAF., e Navarro, F. (2007) Interação da ingestão diária de chá verde (camelliasinensis) no metabolismo celular e na célula adiposa promovendo emagrecimento. Revista Brasileira de Obesidade, Nutrição e Emagrecimento, v. 1, n. 3, p. 27-37.

Annelli, LC et al., (2016) Efeitos funcionais das catequinas do chá verde na redução de gordura corporal. Revista Odontológica de Araçatuba, v.37, n.2, p. 46-51.

Arraes, GCF., eFunchal, C. (2017) Influência dos polifenóis do chá verde na obesidade. Nutrição Brasil 2017;16(1):43-56.

Brasil. Ministério da Saúde. Secretaria de Vigilância em Saúde. Vigilância de fatores de risco e proteção para doenças crônicas por inquérito telefônico - Vigitel, (2018). Disponível em: https://agenciabrasil.ebc.com.br/saude/noticia/201907/obesidade-aumentou-no-pais-entre-2006-e-2018-dizpesquisa. acesso em: 06/07/2021.

Duarte, JLG et al., (2014) A relação entre o consumo de chá verde e a obesidade: revisão. Rbone- Revista Brasileira de Obesidade, Nutrição e Emagrecimento, São Paulo, v.8, n.43, p. 31-39, jan/fev.

Fernandes, DZ et al. (2017) Efeitos do chá verde e do exercício físico sobre a composição corporal de pessoas obesas. Revista do Departamento de Educação Física e Saúde e do Mestrado em Promoção da Saúde da Universidade de Santa Cruz do Sul / Unisc. ano 18 - volume 18 - número 2 - abril/junho.

Gindro, GB., e Veras, KMA (2018) Benefícios do chá verde associado ao emagrecimento. Revista Científica UMC. Edição Especial Pibic.

Lin, J et al. (2005) Greenteapoly phenolepigalloca techingal lateinhibitsadipogenesis and inducesapoptosis in 3t3-11 adipocytes. Obes Res ClinPract. 2005; 13(6): 982-990. disponível em: https://pubmed.ncbi.nlm.nih.gov/15976140/ acesso em: 08/07/2021

Luz, MNC et al. (2017) Chá verde (camelliasinensis): Tratamento alternativo da obesidade. Mostra científica da Farmácia, [s.1.], v. 3, n. 1, jul. 2017. issn 2358-9124. disponível em: http://reservas.fcrs.edu.br/index.php/mostracientificafarmacia/art icle/view/1225. acesso em: 03 jul. 2021.

Martins, RB et al. (2021)Uso potencial do chá verde no tratamento complementar de morbidades e uso de medicamentos, associado ao envelhecimento: Uma revisão. Capítulo 27 do livro: Envelhecimento Humano Desafios Contemporâneos - volume 2. Publicado em: 06 de janeiro de 2021.

Matsubara, S., e Rodriguez-Amaya, D (2006) Teores de catequinas e teaflavinas em chás comercializados no Brasil. Ciência e Tecnologia de Alimentos, Campinas. vol. 26. núm. p. 401-407.

Melo, SS et al. (2009) Efeito do extrato seco do chá verde, chá branco e carallumafimbriata na perda de peso e nas concentrações séricas de glicose e colesterol total em humanos. Rbone-Revista Brasileira de Obesidade, Nutrição e Emagrecimento, São Paulo, v.3, n.18, p. 467-477, nov/dez.

Moresco, GM., eGhisleni, CP (2017) A influência do chá verde (camelliasinensis) na redução do peso corporal. Universidade Regional Integrada do Alto Uruguai e das Missões. Erechim, RS.

Nascimento, CJ., Piloto, JAR., e Tiyo, R. (2017) Nutracêuticos para o emagrecimento: uma revisão. Revista UningáReview, vol.29, n.2, pp.64-69, jan/ mar.

Pazinato, MS et al. (2012) Uma abordagem diferenciada para o ensino de funções orgânicas através da temática medicamentos. Química Nova na Escola, v. 34, n.1: p. 21-25. 
Pires, BC et al. (2021) Camelliasinensis: benefícios no auxílio ao tratamento da obesidade. BrazilianJournalofDevelopment, Curitiba, v.7, n.2, p.15411-15420.

Saigg, NL., eSilva, MC (2009) Efeitos da utilização do chá verde na saúde humana. Universitas: Ciências da Saúde, Brasília, v. 7, n. 1, p. 69-89.

Santos, VS (2019) A química dos chás: o saber popular no ensino de química. Universidade Federal do Recôncavo Bahiano Amargosa, Bahia.

Soares et al. (2007) Avaliação do óleo essencial do chá verde (camelliasinensis) extraído por hidroestilação e soxhlet. Departamento de engenharia química - Universidade Federal Rural do Rio de Janeiro.
Urzedo, NDR (2020) O chá verde e suas propriedades: uma breve revisão bibliográfica abrangendo os anos de 2000 a 2020. Universidade Federal de Uberlândia. Instituto de Química, Uberlândia, MG.

Vilela, MCL., e Souza, MFC (2016) A utilização da camelliasinensisno processo de emagrecimento. Fundação de Ensino e Pesquisa do Sul de Minas. $9^{\circ}$ Congresso Pós Graduação UNIS, MG, 2016. disponível em: http://repositorio.unis.edu.br/ handle/prefix/455. 